\title{
Implementation of Interactive Peer Learning Environment Enhances Learners' Self-Esteem and Self-Efficacy
}

\author{
Ellina Rienovita *, Masashi Taniguchi ${ }^{\dagger}$, Masato Kawahara ${ }^{\star}$, \\ Yugo Hayashi ${ }^{\S}$, Yugo Takeuchi ${ }^{* *}$
}

\begin{abstract}
The study had objective to investigated how learners can be motivated to pass on their knowledge to others using interactive peer learning. Interactive peer learning that encourages teaching other students who seek help enhances learner self-esteem and self-efficacy. An excellent illustration of an interactive peer learning environment is a student who teaches their peer students through question-answer activities. The student's motivation rises while teaching peers and triggers teaching in others by interaction during collaborative learning. The experiment operated under two conditions: a blackboard system (BBS) and a computer-mediated environment (CME). A CME is an interaction model in which the system has the power to select which student will answer the questions, while a BBS is an interaction model whose system does not select the student who will answer the questions. The results found that self-efficacy was higher in the CME than the BBS.
\end{abstract}

Keywords: self-esteem, self-efficacy, collaboration, interactive peer learning environment, motivation.

\section{Introduction}

Educational software using various types of interactive software agents to mediate student interaction has become popular additions to interactive learning environments. Social interaction with other participants in the classroom influences cognitive and affective characteristics[1], [2]. Providing learners with social interactions might increase the uniqueness of pedagogical agents from conventional courseware. A learner can engage in content by interacting with one or more pedagogical agents who may provide information or collaborate with him/her. Pedagogical agents can possess human-like personas to create a social context for more natural learning[3], [4].

\footnotetext{
* Shizuoka University, Hamamatsu, Japan and Indonesia University of Education, Bandung, Indonesia

$\dagger$ Shizuoka University, Hamamatsu, Japan

* Shizuoka University, Hamamatsu, Japan

$\S$ Ritsumeikan University, Ibaraki, Japan

** Shizuoka University, Hamamatsu, Japan
} 
In the present study, the interactive peer learning environment facilitates collaborative learning among students and supports independent learning and generative, self-paced, active learning techniques for each student. Active learning occurs when learners apply a cognitive process to an incoming material process to increase their comprehension of the material [5]. An excellent illustration of an interactive environment is a student who is simultaneously playing two roles: as a member of a student group and also as a person who is teaching other members of this group through question-answer activities. The basic technique is to pose a question that the students first answer individually, and then discuss with a peer and answer again. Whether the first answer is correct remains hidden until the second answer is given. The second answer is generally the correct one. For instance, in the blackboard system (BBS), if a student ignores the questions and hesitates to answer, he/she will not receive any "thanks" from the others. On the other hand, in a computer mediated environment (CME), the agent comes to the student, who then must say "thanks" by typed the text because the agent helps the student answer the questions. "Thanks" [6], [7] is one key factor that improves student self-esteem.

The developed system is question-answer (QA) agent-driven interactive peer learning. A learner can question or answer through interaction with an agent using both CME and BBS. The agent may provide information or encouragement, share ideas and tasks, or collaborate with the learner. The effect of agent-mediated interaction encourages self-esteem and motivation. Therefore, the research questions are first, how can self-esteem improve student motivation? and, second, how does agent-mediated interaction motivate students to teach and learn? The research goal is to establish a peer learning environment via agent-mediated interaction in order to motivate students to teach others using both BBS and CME.

\section{Related Work}

\subsection{Collaborative Learning and Technology}

Learning is often considered a change in the proportional knowledge possessed by an individual. Collaborative learning plays a significant role in the learning process by promoting collaboration among peers to achieve learning objectives together. Such a learning approach encourages brainstorming among the group and increases their engagement and interest in learning activities. Offering an alternative to this view, Vygotsky argued that students can accomplish epistemic tasks in small groups before they individually can achieve the same task and that much individual learning actually results from previous group interactions[8], [9]. According to Vygotsky, individual learners exhibit different developmental capabilities in collaborative situations than when they are working alone. Collaborating peers encourage each other to actively interact by asking questions, explaining and justifying opinions, ar-ticulating their reasoning, and elaborating and reflecting upon their knowledge in CMEs. The nature of collaborative learning systems, which focus on collaboration and communi-cation, has fueled the integration of social network services (SNSs) for expanding func-tionality and usage varieties. SNSs can facilitate learning and skill development outside of formal learning environments by supporting peer-to-peer learning of knowledge and skills, collaboration, diverse cultural expression, development of skills valued in the modern workplace, and a more empowered conception of citizenship[10], [11]. With the integration of SNSs in the collaborative learning environment, learners can communicate with each other anywhere and anytime as long as internet connection is available. Similarly, Boyd \& Ellison argued that SNS can be described as a website or service where people talk to, or connect with other people with same interests. Social network sites have attracted significant media interest because of their rapid rise and expansive user bases, especially among younger people[12]. 
SNSs can provide young people with a space to work out identity and status, make sense of cultural cues and negotiate public life. For example, university students seek social approval through SNSs. Social networking is built on an idea that addresses how people should know, and interact with each other. SNSs such as Facebook are constantly evolving and developing the means of social interaction, which not only disseminates information to families, friends, and colleagues but also acts as a way of meeting and interacting with strangers through a large number of social applications [13]. College students seek social approval from partners or classmates by choosing like- dislike buttons on Facebook. Since students want to be liked by their friends, they perform actions they believe will meet their friends'expectations or impress them. Praise and other positive comments from friends function as rewards for specific behaviors by students and increase their repeated likelihood in the future [14]. In the classroom, the teaching-learning process is the teacher's responsibility. Interaction among students in programming courses happens when they face such programming problems as debugging errors. Students avoid teaching others because that is not their responsibility. One reason they might teach others is to gain approval rewards. Rewards only provide motivation for students who believe that they have a chance to receive them if they make a reasonable effort. Approval from others might just include a simple 'thanks'[6], [7]. Other comments may include such impressions of motivation as: "If other students approve of me and thank me, then I can look at myself and think I'm not so bad because I have some knowledge that I can impart to others, and I'll start liking myself ;" "When having others approve of me, I feel more self-confidence and I like myself more;" "If other people don't like me, then I wonder if I'm a good person, and so I care about what they say about me;" and" If nobody likes you, you probably won't like yourself very much."

\subsection{Programming, Self-Esteem and Self-Efficacy}

Learning to program is often challenging [15] because it requires the absorption of complex new knowledge, strategies, and skills. Winslow argued that learning to program is difficult and beginner programmers suffer from a variety of difficulties and deficits [16]. Programming subjects are generally regarded as difficult and often have higher withdrawal rates. Several other authors observed this problem[17]-[20]. Nagappan et al investigated the use of pair programming in their introductory computing course and reported that pair programmers were more self-sufficient, generally performed better on projects and exams, and were more likely to receive a grade of $\mathrm{C}$ or higher than their solo counterparts [21]. Williams \& Upchurch support the qualitative outcomes of pair programming activities[22]. Pair programming enhances both student learning and satisfaction, and also reduces the amount of support that students require from educators. They also found that team-building and communication skills development was encouraged by such a strategy. In the field of programming, learner propensities must be evaluated to actually apply what they have learned and the confidence they have developed in their ability. A person's computer self-efficacy, defined as their judgment of their ability to complete a task using computers [23], influences not only the decision to enroll in computer courses [24], but also successful performance [25], [26]. A sstudent's programming self-efficacy beliefs focus on individual capabilities to learn and perform programming tasks. These beliefs can be relatively broad, for instance, when referring to general beliefs where one has skills and capabilities to learn and perform programming tasks. Hence, students have self-efficacy beliefs that can range from their overall programming capability to their ability to solve programming problems. Maslow argued that self-esteem is a basic human need and a precondition for self-actualization[27]. He believed that it is related to a "dominance feeling" or a sense of mastery or superiority over others. For example, cognitive balance theories, (including cognitive dissonance) are based on the notion that people have a "need" for cognitive consistency, and in personality psychology, various systems of needs have been proposed[28], [29]. However, the critical scrutiny of many so-called needs has redefined them less as needs 
and more as wants, goals, or desires. This paper argues that interaction among students fuels their own motivation as they teach and learn from each other. A low-skilled programmer taught by a high-skilled programmer is not the responsibility of the latter. Student-to-student interaction in computer programming is the exchange of information and ideas among students about courses in the presence or absence of instructors [30]. Collaboration is an active learning strategy that has been related to increased achievement in engineering students [31], [32]. Whether engaging in casual conversations after class or working together on assigned group projects, those who use collaborative learning strategies have opportunities to share ideas, challenge each other's thinking, and ultimately learn from one another [33]. Research has shown that students who feel confident in their ability to learn and perform well in a course and actively use knowledge-building strategies in their coursework also include collaboration in their repertoire of learning strategies. Iinteraction among students who have already learned group interaction skills spreads information for problem solving by teaching and learning from each other. Student beliefs about their own ability to successfully engage with the topic matter to be learned influence their own self-esteem.

\subsection{Human Agent Interaction}

Intelligent agents are a new paradigm for developing software applications. Intelligent user interfaces can take advantage of embodied intelligence to facilitate human-computer interaction by Embodied Conversational Agent (ECA) systems. An example of a person inter-acting with another person may serve to explain how humans actually interact in their natural context, and demonstrate some of the potential problems with interacting with invisibility. Figure 1 illustrates an agent collaboration to help novice problem-solving in programming. A novice here is defined as someone who does not possess programming knowledge. When the novice begins reading problem specifications, a lack of comprehension of the instruction can cause disorientation. While the novice starts to understand the problem, they can continue to feel lost, this time because they do not know how to begin the programming process. The first error they encounter can trigger strong negative emotions. Subsequent errors can lead to a sense of resignation and reluctance to continue. Collaboration is a commonplace human activity that, increasingly in agent-only and human-agent terms, provides added value in a number of areas, most notably the stimulation and motivation of students, who take respon-sibility for the planning and generation of ideas. 


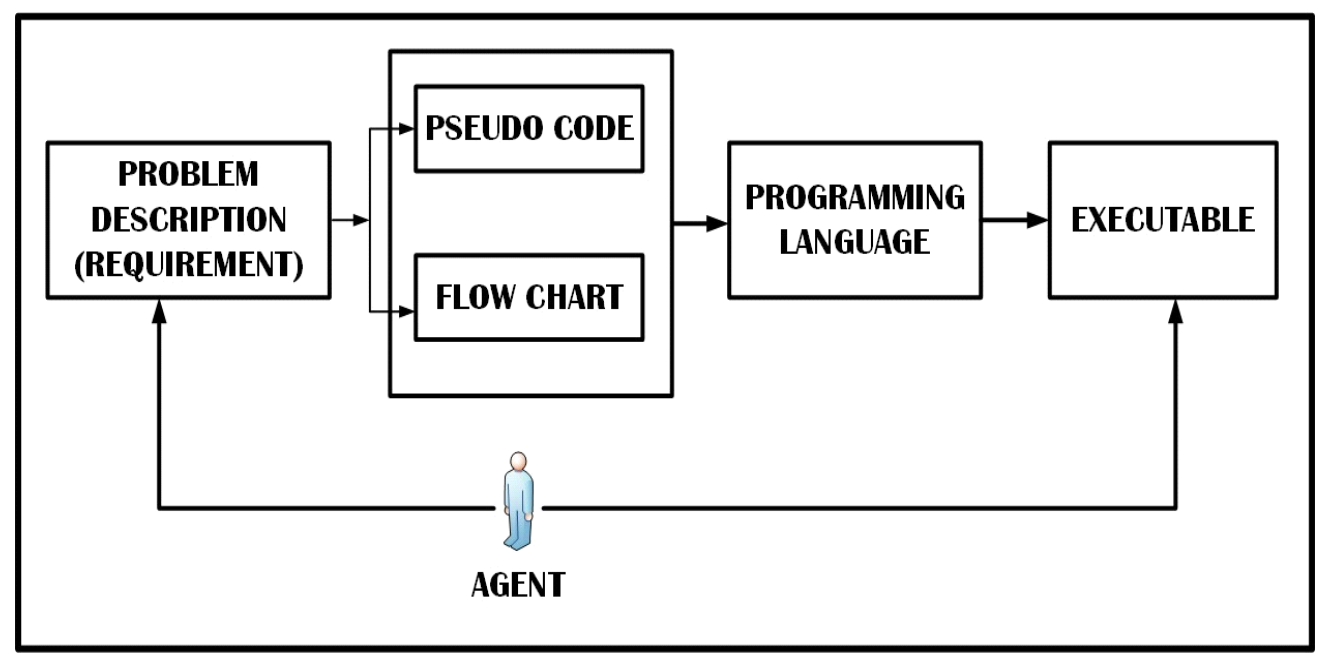

Figure 1. Agent task collaboration

\section{Facilitating Self-Esteem through Interactive Peer Learning Environment}

Peer learning can be defined as the acquisition of knowledge and skills through active help and support among status equals or matched companions. It involves people from similar social groupings who are not professional teachers helping each other to learn and learning themselves through the process. The interaction of students with their peers through various technological devices and the influence of these devices on the interaction among students, have become important research issues as technology increasingly comes into the classroom. Peer tutoring, the use of students as instructors of other students, provides a way to leverage the potential of tutoring to minimize existing limitations[34]. Such activities are believed to provide opportunities for peer tutors to rehearse their knowledge, and more importantly, to integrate new and prior knowledge and generate new ideas. Peer tutoring is often promoted on the grounds that learning can be done by teaching. This view has been expanded to the notion that to teach is to learn twice [35]. The process of preparing to be a peer tutor has been proposed as a way to enhance cognitive processing, such as perceiving, differentiating, selecting, storing, inferring, applying, combining, justifying and responding by increasing attention to and motivation for the task, while necessitating a review of existing knowledge and skills [36]. Student tutors can learn from their teaching experiences[37], [38], which authors refer to as the tutor learning effect. When peer tutoring works, two students benefit simultaneously. Some peer tutoring methods scaffold the interaction 


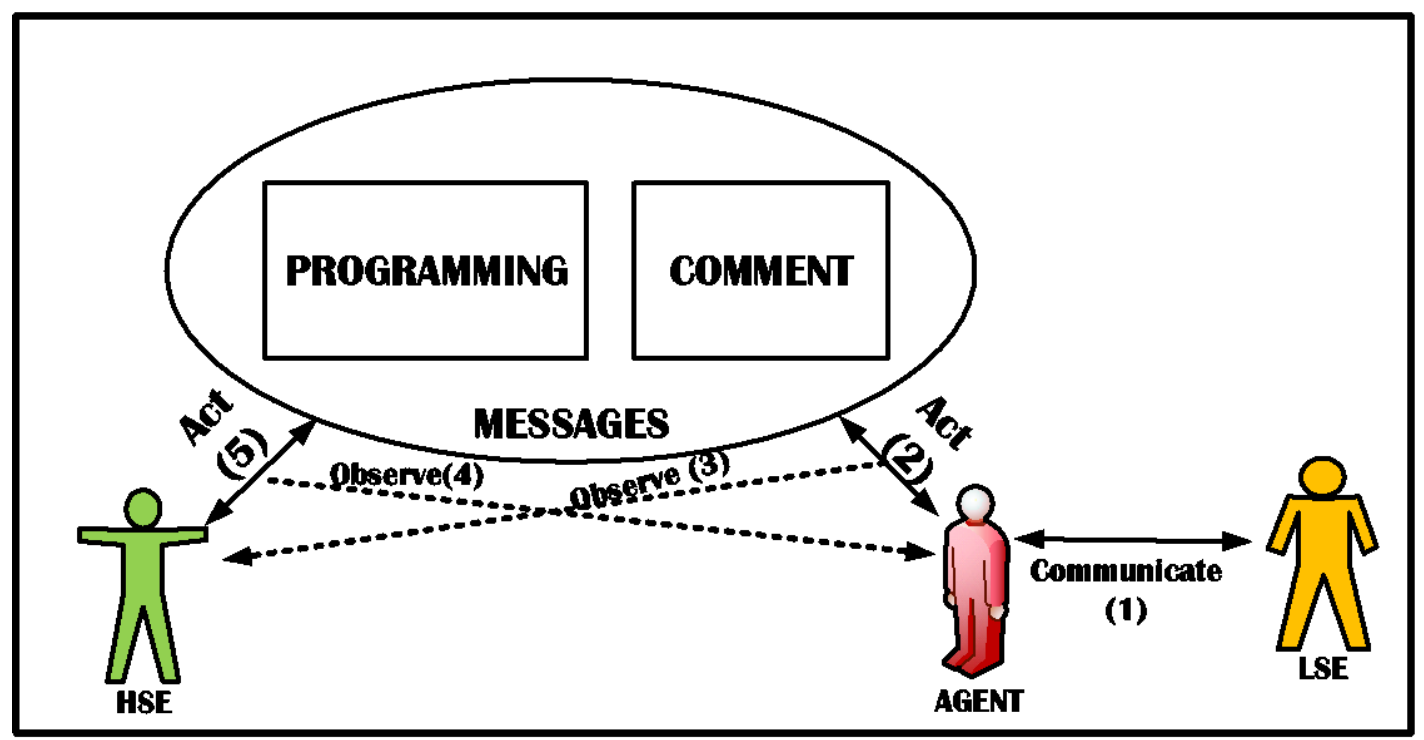

Figure 2. Facilitation of self-esteem through peer learning

with structured materials, while others prescribe structured interactive behaviors that can be effectively applied to any materials of interest. For instance, Figure 2 illustrates how student self-esteem can be facilitated by asking each other questions. An interactive peerlearning envi-ronment involves interacting with a computer system. Examples include, a learner talking with another person (either a peer or a tutor) while responding to the system, a QA agent as an intel-ligent tutoring system and an animated agent. An agent and a student with low self-esteem (LSE) communicate when the latter faces a difficult programming problem. The agent receives messages from the LSE student about programming and then asks for and delivers messages from a high self-esteem (HSE) student, who gives suggestions such as correct solutions to the agent. This agent suggests the correct answer to the LSE student, who understands that the mes-sages from the agent are based on suggestions from HSE student. Furthermore, LSE students with similar programming problems can teach each other solution. Interaction among learners is useful because it enhances self-esteem and improves programming skills.

\section{Investigation}

This study experimentally investigated how a learner who has gained knowledge can be motivated to pass that knowledge on to others using social learning environments. The development of such systems can facilitate learners' self-esteem using agent-driven peer learning environments. The hypotheses tested in our study are based on questions from a BBS and CME. The former is a web-based scheme that volunteers to answer questions. The CME is agent-mediated interaction whose responsibility is to answer questions. Changes in learning efficacy and improvement in self-esteem and willingness increase the students' self-esteem and self-efficacy, and also improve their behavior.

\subsection{Computer based Simulation}

Computer modeling and simulation relates to the manipulation of a computational model to enhance the analysis of a system's behavior and to assess strategies for its functioning in descriptive or predictive modes. A simulation is the discernible manifestation of a model's 
performance, using a computer program that provides insights into the system or application under investigation. A simulation model applies the computing algorithms, mathematical expressions, and equations that encapsulate the behavior and performance of system in real-world scenarios. Models are commonly defined in order to study and explain observed phenomena or to predict future phenomena [39].

For example, this simulation compared the model and random algorithms. The model's purpose is to validate the use of its algorithm to selectively improve self-esteem and self-efficacy. The simulation compared the self-esteem model algorithm to a random algorithm under this condition and identified a great increase in self-efficacy. The ability of students when they start tasks outside of the normal distribution is illustrated by the probability that they will correctly answer the questions, which denotes how prepared they are to take certain exams. One perspective is that the level of complexity at which a simulation becomes

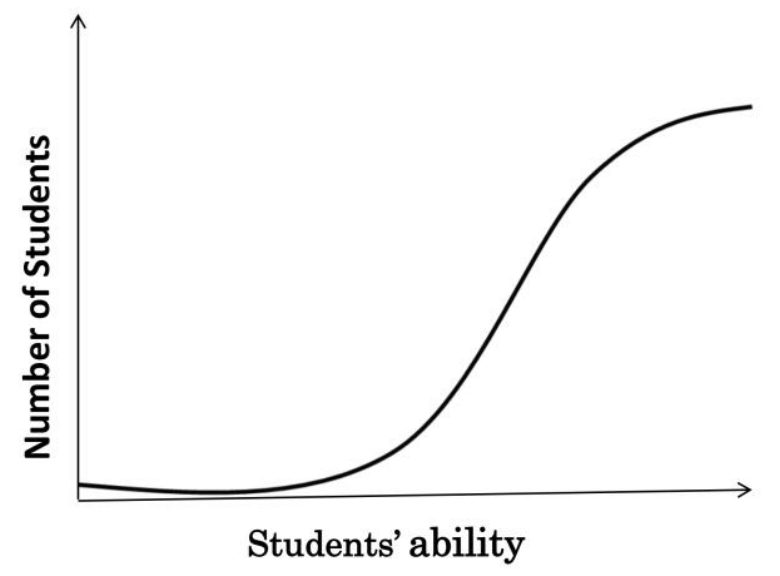

Figure 3. Distribution of students' ability

"useful" depends on the level and understanding of the student [40]. What may be obvious to a more experienced student may be a novel and difficult concept to a younger student or someone studying at a lower level, which impact the distribution of the initial capacity shown in Figure 3. This distribution has many lower-capacity learners, and fewer answers are possible when too many learners ask questions.

\subsection{Computer Simulation Parameters}

In the simulation, questions were answered to the students' own satisfaction by increasing the level of their ability to recognize their own performance. Furthermore, experimenters helped solve self-efficacy knowledge tasks by configuring the answers according to the 
participant's time limitation. This method of building self-esteem might increase self-efficacy. For example, self-efficacy can be raised by assisting with performance issues using a relatively higher-level learner who provides hints about problems through the system, thus improving this learner's self-esteem by letting him/her answer. The computer simulation parameters are given in Table 1.

Table 1. Simulation parameters

\begin{tabular}{|l|l|}
\hline Number of questions & Number of learners' questions \\
\hline Time & Elapsed time from when the learner' starts to learn. \\
\hline Number of total answers & Number of times that the learner answered questions. \\
\hline Successful answers & $\begin{array}{l}\text { Number of times that the learner answered questions cor- } \\
\text { rectly. }\end{array}$ \\
\hline Failed answers & $\begin{array}{l}\text { Number of times that the learner answered questions in- } \\
\text { correctly. }\end{array}$ \\
\hline Problem progress & Progress status of the learner's efforts to answer questions. \\
\hline Self-Esteem & Self-esteem of the learner in answering questions. \\
\hline Self-Efficacy & Self-efficacy of the learner in answering questions. \\
\hline $\begin{array}{l}\text { Question probability of } \\
\text { occurrence }\end{array}$ & Probability that the learner will ask the system a question. \\
\hline Answer probability & $\begin{array}{l}\text { Probability that the learner answered questions after } \\
\text { he/she asked the system a question. }\end{array}$ \\
\hline $\begin{array}{l}\text { Answer success proba- } \\
\text { bility }\end{array}$ & $\begin{array}{l}\text { Probability that the learner correctly answered a question } \\
\text { after asking the system a question. }\end{array}$ \\
\hline
\end{tabular}

\subsubsection{Participants}

A total of 30 people participated in this simulation. The simulation divided the initial capacity into three stages of upper, middle and low learners. The learners' initial self-esteem and self-efficacy were $10 \%, 80 \%$ and $10 \%$. Table 2 explains the simulation's environment, which includes three student actions: (1) solving problems; (2) asking questions; and (3) answering questions.

Table 2. Simulation environment

\begin{tabular}{|l|l|}
\hline Number of learners & 30 \\
\hline Percentage students' algorithm ability when & $\begin{array}{l}\text { High } 10 \% \text {, middle } 80 \% \text {, and low } \\
10 \%\end{array}$ \\
\hline starting a task & $\begin{array}{l}\text { Percentage of students' self-esteem when starting a } 10 \% \text {, middle } 80 \% \text {, and low } \\
\text { group task }\end{array}$ \\
\hline Percentage of students' self-efficacy when starting & $\begin{array}{l}\text { High } 10 \% \text {, middle } 80 \% \text {, and low } \\
10 \%\end{array}$ \\
\hline a task & 5400 seconds \\
\hline Time & 10 stages \\
\hline Task & 100 times \\
\hline Number of trials &
\end{tabular}

\subsubsection{Instruction and Procedures}

The procedure in this study compared simulations between the model and random algorithms (Figure 4 and Figure 5). This simulation verifies based on a hypothesis that chooses the system's best response to enhance self-esteem. The model algorithm selects answers 
from students who have greater task progress than question progress. It also selects students with the largest gap between self-efficacy and self-esteem. The random algorithm selects answers from students who have made more task progress than question progress and also randomly selects students. The random algorithm provides the system with selected responses that are answered by the students who have made greater task progress than question progress. It also selects students with the largest gap between self-efficacy and self-esteem.

Figure 6 describes the self-esteem and self-efficacy in this simulation. The former can be improved by answering questions. Higher self-esteem reflects how more positive the learning and assistance will be, as well as the challenges that achieve probability, the question occurrence probability, and the increases in the answer probability. As the challenge progresses, self-efficacy improves the knowledge level and reduces challenges that exceed the allotted time without any progression, and self-efficacy is reduced. Authors can also

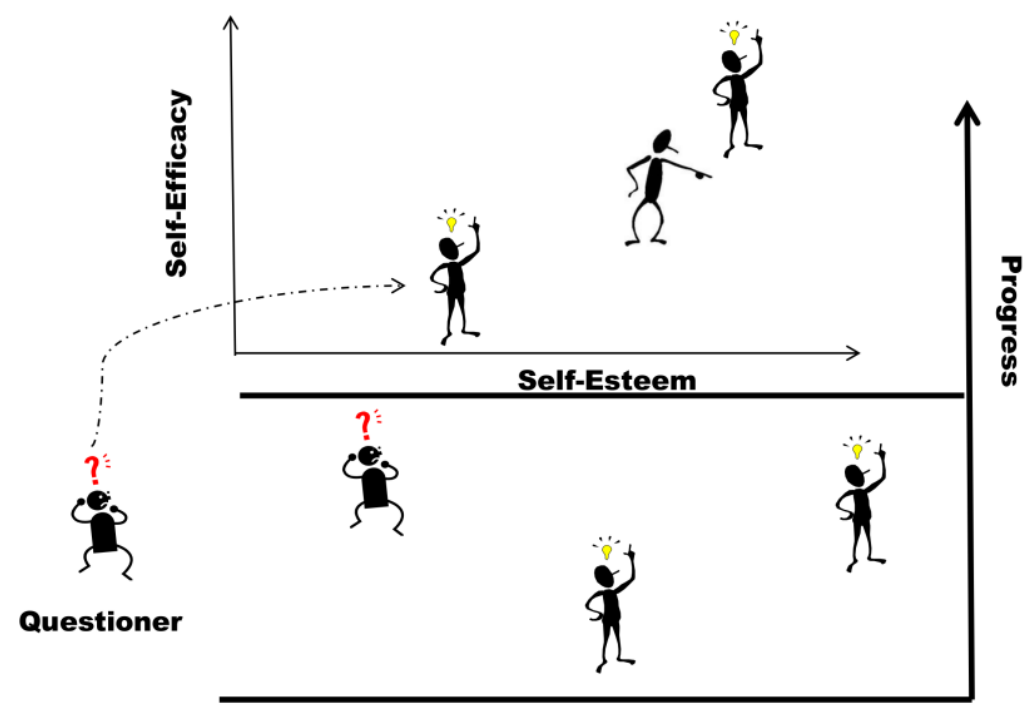

Figure 4. Model algorithm

improve the answer probability of successes because the self-efficacy confidence of their knowledge is high. In addition, each learner interacts with a question and an answer. Figure 7 describes the parameter changes during the interactions that were generated in the simulation. Using these parameters, the simulation experimentally showed the validity of using both algorithms to select the differences between self-esteem and self-efficacy to provide a model for better learning. 


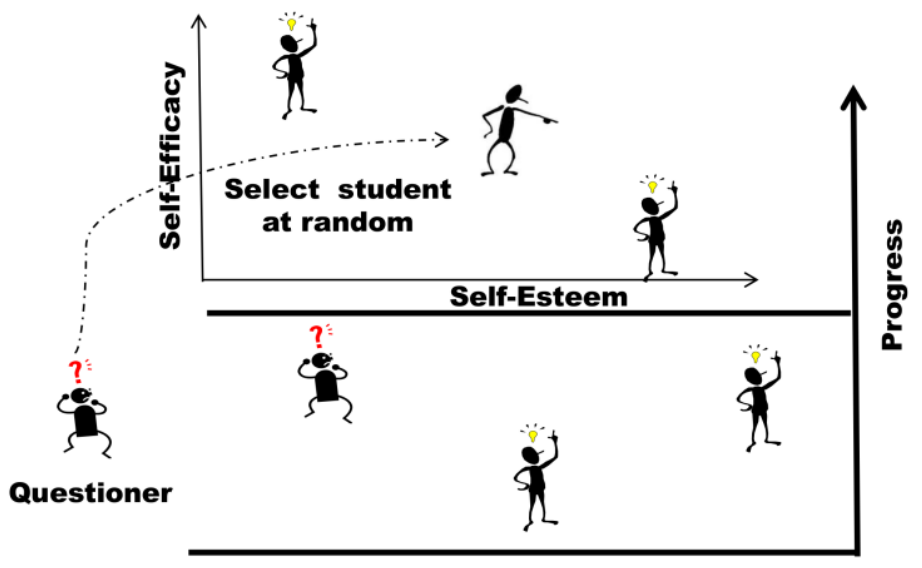

Figure 5. Random student selection

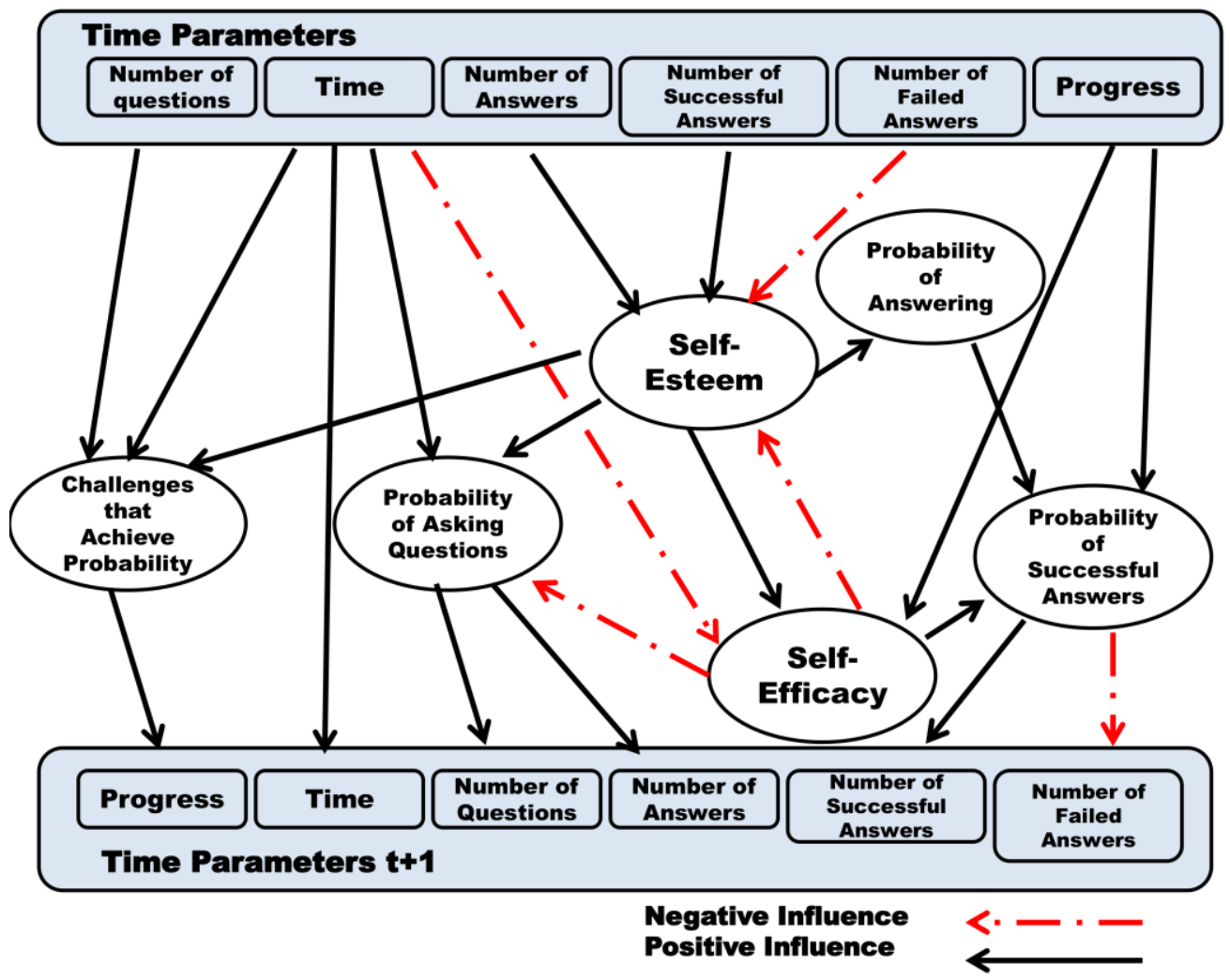

Figure 6. Network diagram of algorithm 


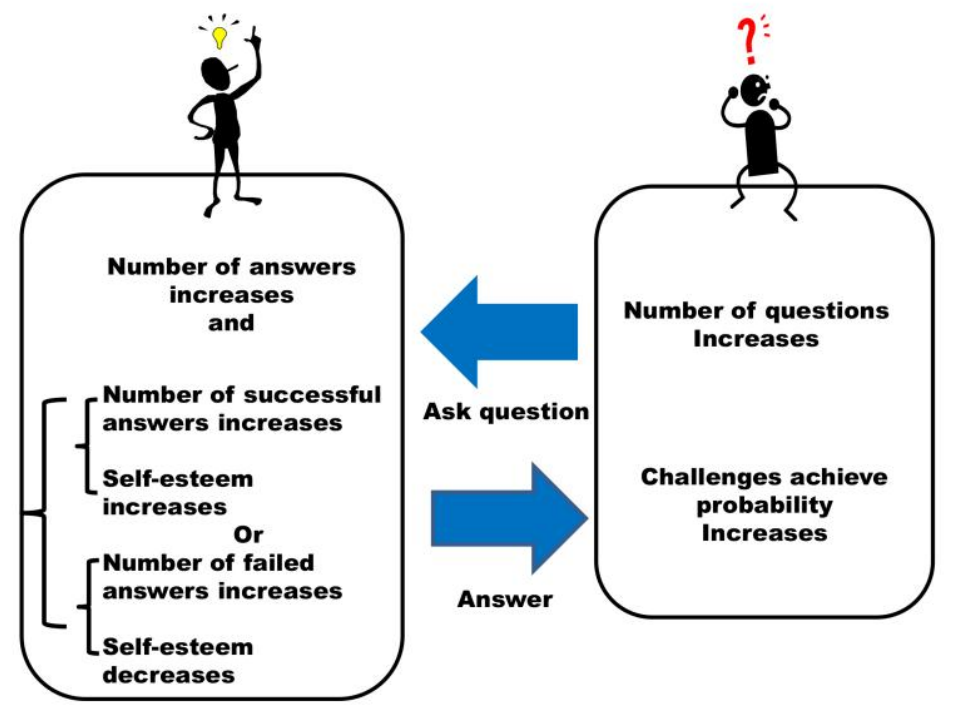

Figure 7. Interaction parameters of computer simulation

\subsubsection{Result}

Self-esteem at 2400 (s) changed dramatically (Figure 8) because at this time as seen in Figure 9 the results for self-esteem were starting to improve by answering questions. The model algorithm improved self-esteem much more than the random algorithm when questions began to surface. In other words, the simulation caused the intended interaction: greater improvement in self-esteem. The increase in self-esteem is greater at 2400 (s), and a difference arose between the random and model algorithms in subsequent challenges, with the number of questions becoming positive for learning. In comparing the random algorithm with the model algorithm for self-efficacy in Figure 10 and Figure 11 at 3000 (s), subsequent self-efficacy improve when the progress of the problem improved, and selfefficacy decreased when the challenges stagnated. This effect helped to solve the algorithm's tasks and improved the knowledge level at which a person considers himself/herself due to self-esteem dropping with the passage of time. Fur-thermore, the difference in timing is generated in the same way, and for the same reason, between the algorithms in the progress problem. At 3000 (s) there was little change. The degree of the challenges' difficulty increased and self-efficacy further improved when a student's ability to solve difficult tasks grew even as performance decreased due to self-efficacy issues immediately following learning after time elapsed, presumably because they canceled each other. The authors also identified the number of questions and the difference in the number of responses. This 


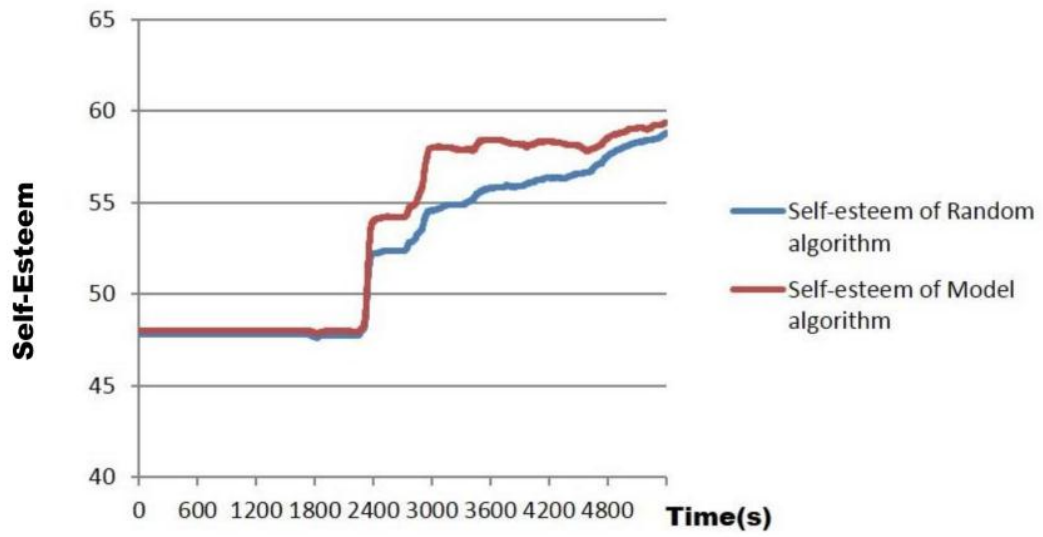

Figure 8.Transition of self-esteem

algorithm selects answers from students who have already made more progress with the tasks. If a learner is struggling to complete the question task, the teacher will give answers. By focusing

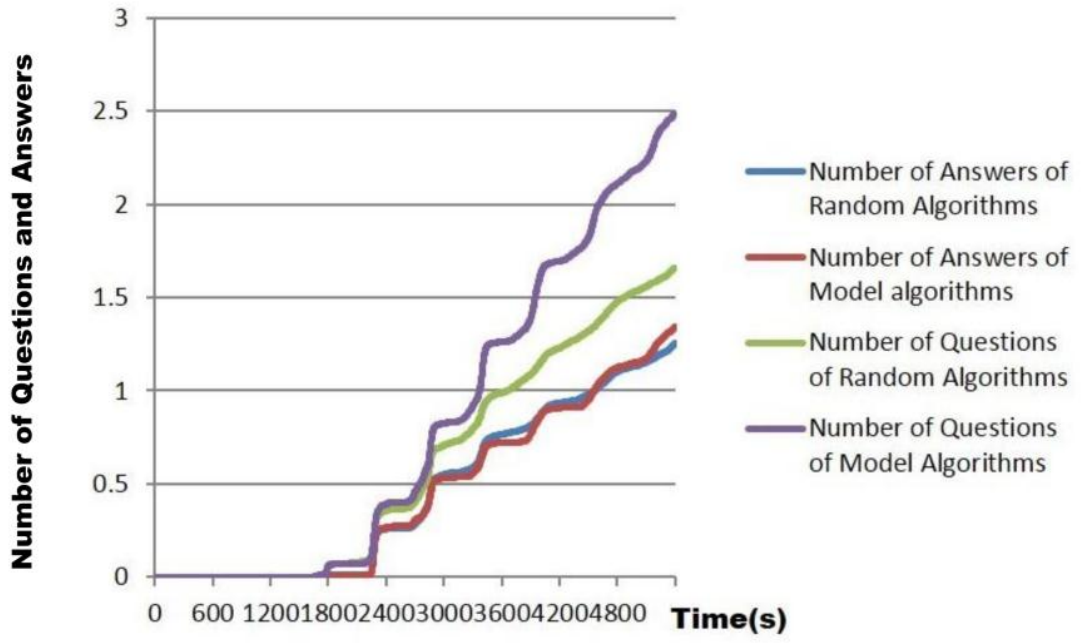

Figure 9.Transition of number of questions and answers 


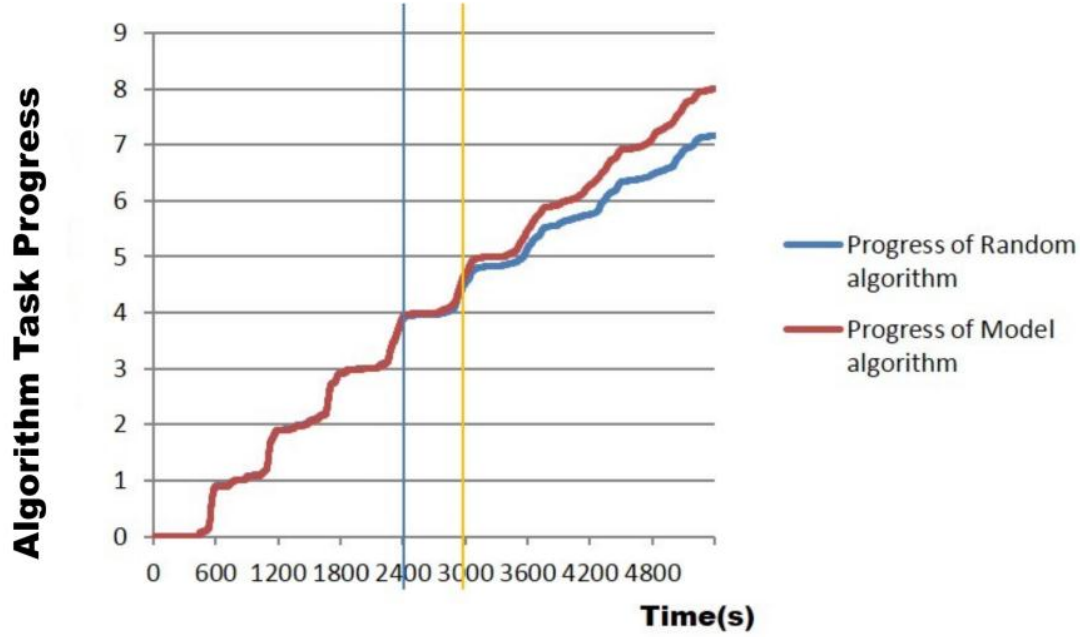

Figure 10.Transition of progress

on the number of responses, experimenters compared the random and model algorithms and identified few differences between them, even though self-esteem did greatly increase. This improvement in self-esteem to an appropriate level by seeking help was significantly better for the compared algorithm based on the model algorithm. With a learning support system, self-esteem can be improved by peer-learning. Since these results accord with experimenters' hypothesis, a simulation's computer can implement the transition of self-esteem based on a comparison between the model and random algorithms. 


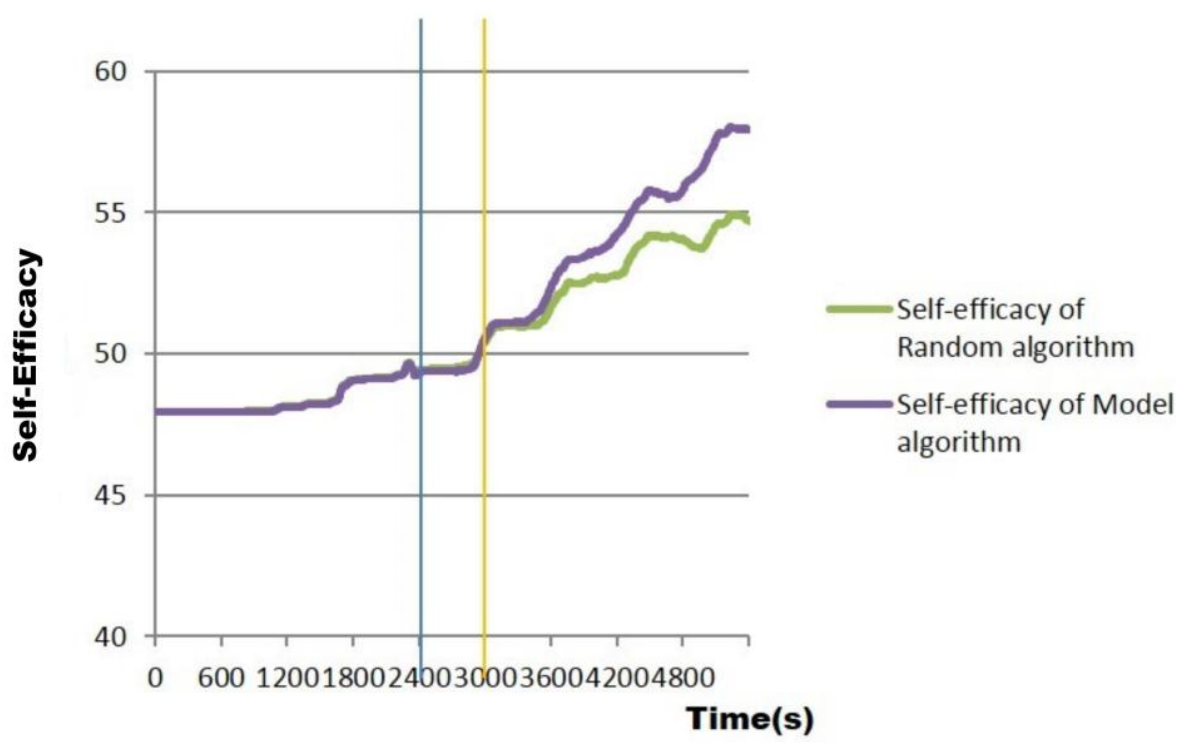

Figure 11.Transition of self-efficacy

\subsection{Experiment}

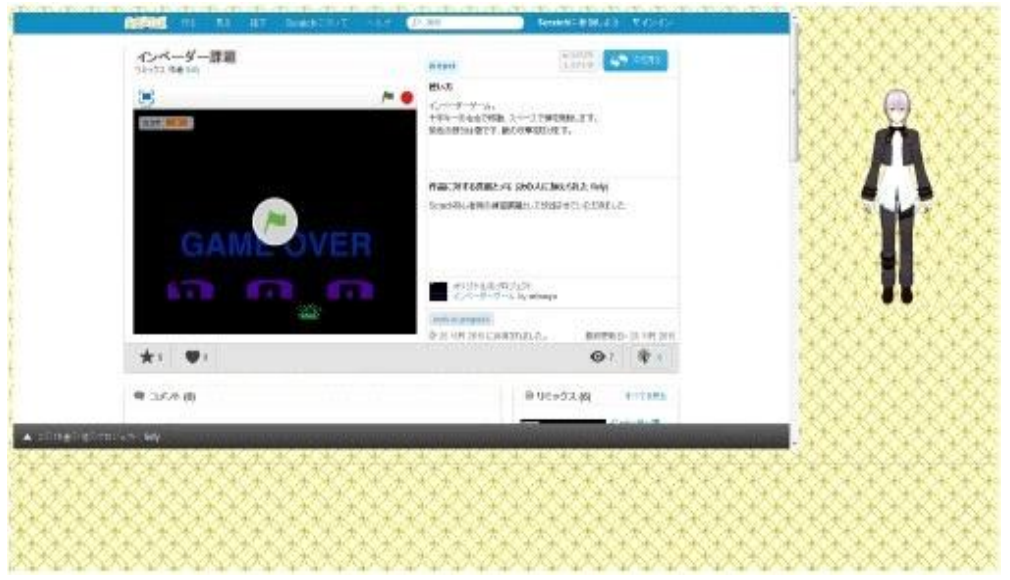

Figure 12. Question-Answer (QA) Agent 


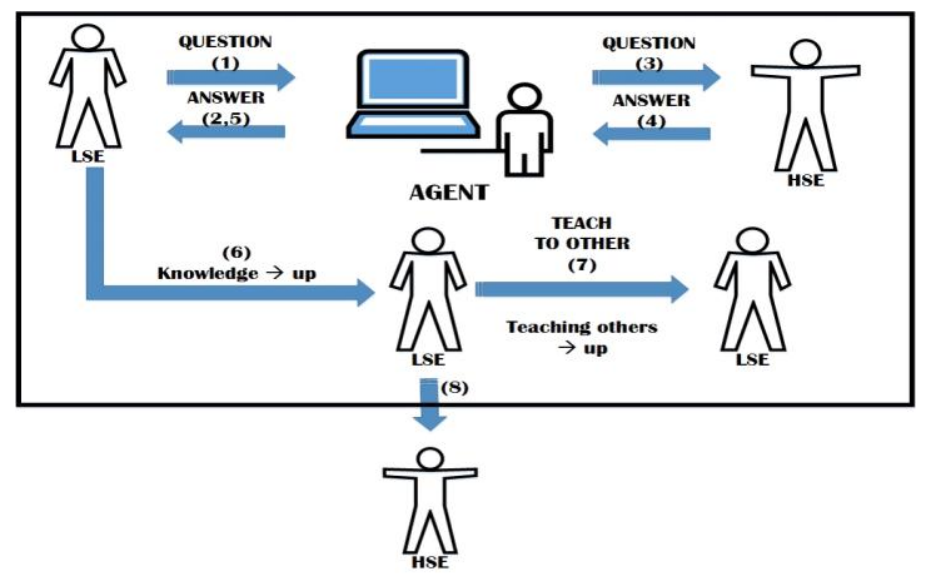

Figure 13. Teaching others

Present study investigated how a learner who has gained knowledge can be motivated to pass that knowledge on to others using interactive peer learning environments. The development of such systems can facilitate the learners' self-esteem using agent-driven interactive peer learning environments. The hypotheses tested in these experiment are based on questions from BBS and CME. Experimenters constructed a computer learning scheme called the question-answer system (QAS). Figure 12 shows the QA agent character that is displayed on the screen every 30 minutes. The QA agent is a unique use of the pedagogical agent and adopts a metaphor to simulate peer interaction among students to exploit the cognitive and affective gains of human-mediated peer-learning. The participants learn by programming tasks through the QAS in Scratch programming language ${ }^{\dagger \dagger}$ by typing text. The participant and agent behavior including voice was recordable via camera recorder. Each participant was assigned a headset and, a computer with a monitor for interaction mediated by the agent during the interactive session. If there is no interaction between the student and agent, the agent disappears. However, if the student needs the agent's help, he/she would press a keyboard key. The learner can learn programming tasks through interacting with the QA agent. Figure 13 shows that students with low self-esteem asked the agent questions. If the agent had an appropriate answer, then it directly provided the answered by searching through the question-answer database. If the agent did not have an appropriate answer, it asked the HSE students, who then provided the correct answers to the agent. The agent correctly answered the LSEs that also understood how to solve the programming problems. LSEs encouraged themselves by teaching other LSEs.

\subsubsection{Participants}

The experimental study was carried out across the BBS and the CME with a total of 30 participants in the two experiment conditions. There were 15 people in both conditions in five groups of three: two males and 1 female. Thirteen were from the Design University and 17 were

\footnotetext{
$\dagger \dagger$ Scratch.mit.edu
} 
company employees. Their ages ranged from 18 to 24 years and the mean was 22.5 years (S.D $=$ 0.50 ). As an observation item, the questionnaire used a 7-point scale to evaluate each item from 1 (completely agree) to 7 (completely disagree) and posted a neutral statement of Mimura \& Griffiths' translated version of Roesenberg's self-esteem scale [41]. This study coordinates personal challenges rather than the cooperation of group challenges. In addition, dependent variables include learners' self-efficacy in the programming task, and self-esteem toward the QA agent. The participants answered the questionnaires to classify self-efficacy and self-approval, from which experimenters obtained the total self-efficacy and self-approval scores. By conducting questionnaires before and after the experiments, observer's observed changes as documented in Table 3.

Table 3. Self-efficacy and Self-approval questionnaire

\begin{tabular}{|l|l|}
\hline Statements & Corresponding index \\
\hline I'm generally satisfied with myself. & Self-approval \\
\hline Sometimes I think that I am totally useless. & Self-efficacy \\
\hline I feel that I have quite an advantage. & Self-approval \\
\hline I am good at something as most people. & Self-efficacy \\
\hline I don't feel very proud of anything about myself. & Self-efficacy \\
\hline Sometimes, I strongly feel that I am more useless than others & Self-efficacy \\
\hline I feel that I am at least as worthwhile as other people. & Self-efficacy \\
\hline I sometimes wish that I had a little more respect for myself. & Self-approval \\
\hline I sometimes feel left behind. & Self-approval \\
\hline I generally think positively of myself. & Self-approval \\
\hline
\end{tabular}

\subsubsection{Instruction and Procedures}

The experiment was conducted during a regular session of an introductory programming course. The participants were randomly assigned to one of the four conditions. They learned and performed computer programming tasks by Scratch through interactive peer learning. The time limitation for their programming tasks was 70 minutes. The programming experiment was structured as follows:

1. 15 minutes: Participants were given a brief written introduction about the experiment.

2. 10_minutes: Participants filled out pre-questionnaires before the programming tasks.

3. 35_minutes: Experiment: participants did programming tasks.

4. 10_minute: Participants filled out post-questionnaires after the programming tasks.

Figure 14 shows how the students were instructed to do the programming tasks and describes the time allotments.

1. The student's interaction triggers a question from user_2 when he gets a programming problem task.

2. At time-1, user-2 asks the agent a question. If the agent has an appropriate answer, he gives it to user-2 by searching through the question-answer database.

If the agent does not have an appropriate answer, he asks user-3 (who has already finished the task) to answer the question because user-3 has an original answer.

4. Based on the answer given to the agent by user- 3 , user- 2 completes the programming task and continues to the next programming level at time-2; however user- 2 is unsatisfied because she feels the programming task answer is not her own original answer.

5. User-2 has enough knowledge to finish the programming task in time-2.

6 . Her self-esteem and self-efficacy increase while teaching user-1, who finishes the programming task by time- 3 by helping answer the task. 


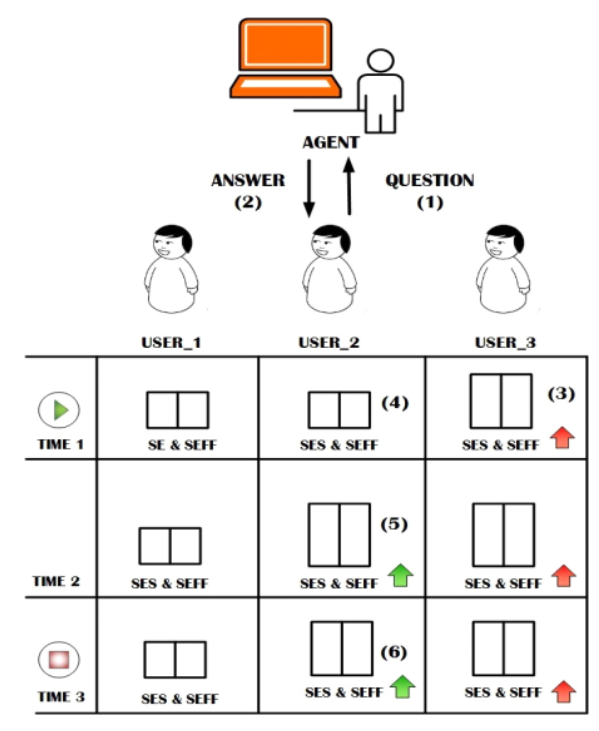

Figure 14. Agent-mediated interaction improved Self-Esteem(SES) and Self-Efficacy (SEFF)

\subsubsection{Results}

Table 4 shows the averages of the pre- and post-questionnaires for self-approval intentionality on BBS before and after the experiment. As seen in Figure 15 and Figure 16 self-approval in BBS had a high F-value of 2.7564 and p-value of $<.01$, and self-efficacy CME had a high F-value of 2.7564 and p-value of <.10). Differences occured when the number of participants increased. Learners strongly desired confidence in all of their answers after learning with the agent. However, their degree of confidence in the answers from their partners' decreased when their feelings of self-efficacy decreased.

Table 5 shows the average self-confidence questionnaire answers. Experimenters analyzed statistically significant differences in the self-esteem scores in each experiment condition by a fixed factor univariate analysis of variance (ANOVA). The possibility of competence feedback and recognition implies a particular degree of external performance evaluation. The anticipation of a performance evaluation can affect motivational orientations and task involvement during task performance, and these motivational processes might influence subsequent interest in the task. 
Table 4. Average pre-and post-questionnaire

\begin{tabular}{|c|c|c|c|c|}
\hline & $\begin{array}{c}\text { Average of } \\
\text { CME } \\
\text { Self-approval }\end{array}$ & $\begin{array}{c}\text { Average of } \\
\text { CME } \\
\text { Self-efficacy }\end{array}$ & $\begin{array}{c}\text { Average of BBS } \\
\text { Self-approval }\end{array}$ & $\begin{array}{c}\text { Average of BBS } \\
\text { Self-efficacy }\end{array}$ \\
\hline Pre-Questionnaire & 18.7 & 19.1 & 17.9 & 21.7 \\
\hline Post-Questionnaire & 24.6 & 17.3 & 20.4 & 20.5 \\
\hline
\end{tabular}

Table 5. Average expectation degree of answers

\begin{tabular}{|c|c|}
\hline Participants & Average expectation degree of answers \\
\hline CME & 4.33 \\
\hline BBS & 3.41 \\
\hline
\end{tabular}

Rewards are informative and motivating. As students tackle tasks, they learn which actions lead to success and which to failure. The anticipation of desirable outcomes motivates students to persist in their learning. Rewards enhance self-esteem when they are linked to a student's accomplishments and symbolize that the student has actually progressed. However, rewards offered for task participation do not convey the same type of progress information. Figure 17 illustrates the significance from BBS and a tendency where self-esteem statistics significantly increased by $1 \%$ in CME (number of effective answers $30,(\chi 2=2.91, \mathrm{~d}=1, \mathrm{p}=0.0878(<.10)$ ). Table 6 provides the responsibility for giving answers which is statistically significantly higher in CME learners $(1 \%$ significantly $(\mathrm{F}(1.29)=17.20, \mathrm{p}<.01)$. The difference was reflected in

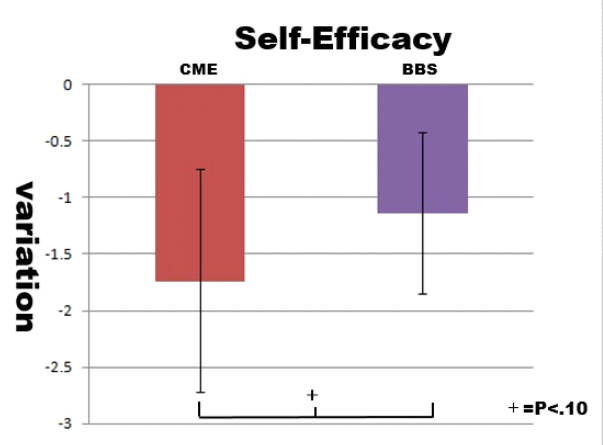

Figure 15. Self-Efficacy result 


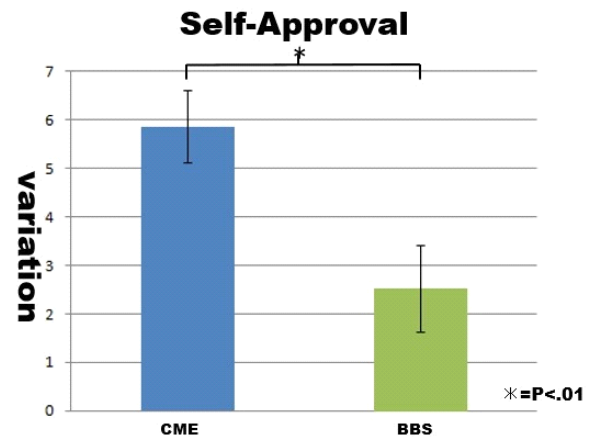

Figure 16. Self-Approval result

self-esteem because the responsibility for answers changed in BBS and CME.

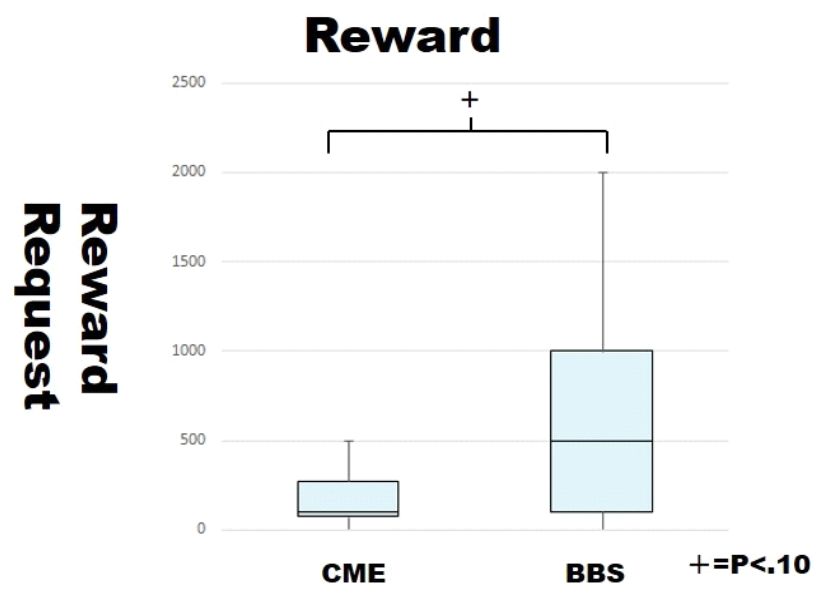

Figure 17. BBS and CME of self-esteem scores 
Table 6. Average answer responsibility

\begin{tabular}{|c|c|}
\hline Experiment & Responsibility for answers \\
\hline $\begin{array}{c}\text { Computer mediated environment } \\
(\mathrm{CME})\end{array}$ & 5.2 \\
\hline $\begin{array}{c}\text { Blackboard system } \\
(\mathrm{BBS})\end{array}$ & 3.13 \\
\hline
\end{tabular}

\section{Discussion}

\subsection{Simulation Evaluation}

The learning content is problematic when a clear answer exists. By learning who is facing a challenge the algorithm's questions provide assistance in simulation settings where about $80 \%$ of the learners successfully answered the questions. In the current simulation program, when responders failed to answer, the applied simulation lowered the self-esteem of the responders who had high self-esteem. However, since actual comparisons are difficult under the same learning conditions because starting motivation and capacity differ for each learner, finding an optimal interaction relationship is challenging.

Therefore, the observer's performed a simulation that generated the intended interaction of learners under various conditions to estimate the optimal learner interactions. The number of differences in questions equaled the number of responses. The algorithm selected a helper, if the learner was ahead on question points because no observer be assumed to answer the question. In the future, for better quality simulation, researchers must adjust the type and the degree of question difficulty.

\subsection{Experiment}

In the agent-mediated interaction among students learning and performing programming tasks in Scratch, both groups participated in question-answer activities. Self-efficacy was lower in the CME. Most of the questions were answered within 5 to 10 minutes in the BBS. The numbers of questions also fell as the experiment progressed. The average numbers of questions in Table 7 are statistically significantly different. Many of the questions arising between 10 to 15 minutes in the CME were asked because the participants understood the problem based on their own thinking. Participants shared the questions and answers with others in the CME. Student self-efficacy in the CME was the same as in the individual learning, where the number of questions was reduced. According to Bandura the most functional efficacy judgments tend to slightly exceed what one can actually accomplish, and this overestimation serves to increase effort and persistence [42]. Efforts to decrease students' relatively high self-appraisals should be discouraged. 
When they accurately understand what they know and do not know, however, students might be able to effectively deploy appropriate cognitive strategies while engaging in an academic task [43].

Table 7. Average number of questions

\begin{tabular}{|c|c|c|c|c|}
\hline \multirow{2}{*}{$\begin{array}{c}\text { Experimental condition } \\
\text { (minutes) }\end{array}$} \\
\cline { 2 - 5 } & $5-10$ & $10-15$ & $15-20$ & $20-25$ \\
\hline $\begin{array}{c}\text { Computer-mediated environment } \\
\text { (CME) }\end{array}$ & 4.30 & 6.11 & 3.42 & 3.00 \\
\hline $\begin{array}{c}\text { Blackboard system } \\
\text { (BBS) }\end{array}$ & 4.33 & 2.33 & 3.13 & 3.41 \\
\hline
\end{tabular}

\section{Conclusion}

In this paper, the authors introduced an interactive peer-learning environment that improves self-esteem and student motivation by focusing on the interaction among learners during collaborative learning. This work further investigated how learners can be motivated to pass on their knowledge to others using an interactive peer learning environment. A learning system is a teaching and educational environment placed within an agent-mediated interaction system. A key characteristic of these sessions is that students work together and learn from each other through a question-answer process. To support interaction among students, a QA agent provided tools that facilitate involvement in studies and interaction with others in the course. The evidence shows that learners tend to enhance their own beliefs of self-efficacy based on their perceptions of peer models. Peer tutoring can be rewarding for both the students who receive tutoring and the tutors. Progress has already been made in developing innovative programs that help tutoring participants achieve meaningful academic gains. Peer learning builds on the individuals' strengths and mobilizes them as active participants in the learning process; furthermore, it encourages personal and social development.

The authors also observed that reward can be one type of motivator. From the beginning, learning how to assist others provides opportunities to give help. Helping and learning from others are positive experiences that increase self-esteem. Even receiving a simple 'Thanks' is a critical factor in promoting a student's motivation because the agent confers approval upon students who have knowledge (student's level of understanding) and gives them confidence to continue teaching others [44]. Learning by teaching others increases the learners' self-efficacy. These activities focus on students' motivation by promoting an interactive and positive framework within which students have opportunities to learn from one another and create a learning community. Due to the uniquely demanding requirements of learning programming, interaction 
among students encourages programming skills.

\section{Acknowledgement}

Funding for the present study was provided in part by JSPS KAKENHI Grant in Aid for Challenging Exploratory Research no. 15K12410

\section{References}

[1] E. A. Skinner and M. J. Belmont, "Motivation in the classroom: Reciprocal effects of teacher behavior and student engagement across the school year.," J. Educ. Psychol., vol. 85, no. 4, pp. 571-581, 1993.

[2] R. E. Sutton and K. F. Wheatley, "Teachers'emotions and teaching: A review of the literature and directions for future research," Educ. Psychol. Rev., vol. 15, no. 4, pp. 327-358, 2003.

[3] A. L. Baylor and Y. Kim, "Simulating instructional roles through pedagogical agents," International Journal of Artificial Intelligence in Education, vol. 15, no. 2, pp. 95-115, 2005.

[4] J. Holmes, "Designing agents to support learning by explaining," Comput. Educ., vol. 48, no. 4, pp. 523-547, 2007.

[5] C. Meyers and T. B. Jones, Promoting Active Learning: Strategies for the College Classroom (Jossey Bass Higher and Adult Education Series). Jossey-Bass, 1993.

[6] E. Rienovita and Y. Takeuchi, "Encouragement of skill mastering motive based on need for approval and Interaction," in Human Interface, pp. 235-238, 2014. (In Japanese)

[7] E. Rienovita, M. Taniguchi, M. Kawahara, Y. Hayashi, and Y. Takeuchi, "Enhancement of learning interaction by need for approval," in Human Interface, 2015, pp. 323-326. (In Japanese)

[8] L. S. Vygotsky, Mind In Society. 1930.

[9] L. S. Vygotsky, Mind in Society: The Development of Higher Psychological Processes. Harvard University Press, 1978.

[10] T. J. Damrich, "Confronting the challenges of change," Circuit World, vol. 21, no. 1, pp. 2-3, 1994.

[11] M. Itō, D. Okabe, and M. Matsuda, "Personal, Portable, Pedestrian-Mobile Phones in Japanese Life," The MIT Press, 2006.

[12] D. M. Boyd and N. B. Ellison, "Social network sites: Definition, history, and scholarship," J. Computer-mediated Commun., vol. 13, no. 1, pp. 210-230, 2007.

[13] N. Friesen and S. Lowe, "The questionable promise of social media for education: Connective learning and the commercial imperative," J. Comput. Assist. Learn., vol. 28, no. 3, pp. 183-194, 2012. 
[14] W. W. Hartup, "Peer relations," in Handbook of Child Psychology: Formerly Carmichael's Manual of Child Psychology, John Wiley \& Sons, 1983.

[15] A. Robins, J. Rountree, and N. Rountree, "Learning and teaching programming: A review and discussion," Comput. Sci. Educ., vol. 13, no. 2, pp. 137-172, 2003.

[16] L. E. Winslow, "Programming pedagogy - A psychological overview," ACM SIGCSE Bull., vol. 28, no. 3, pp. 17-22, 1996.

[17] T. Jenkins, "On the difficulty of learning to program," Diffic. Learn. to Progr., vol. 4, pp. 53-58, 2002.

[18] S. Dehnadi, "Testing programming aptitude," Annu. Work. Psychol. Program., pp. 22-37, 2006.

[19] R. Lister, B. Simon, E. Thompson, J. L. Whalley, and C. Prasad, "Not seeing the forest for the trees: Novice programmers and the SOLO taxonomy," in Proceedings of the 11th annual SIGCSE conference on Innovation and technology in computer science education - ITICSE '06, 2006, pp. 118-122.

[20] C. P. Reddy, "Analysis of teaching computer programming in Indian Context," $J$. Eng. Educ. Transform., vol. 28, no. 4, pp. 50-55, 2015.

[21] N. Nagappan et al., "Improving the CS1 experience with pair programming," in Proceedings of the $34^{\text {th }}$ SIGCSE Technical Symposium on Computer Science Education, vol. 35, no. 1, p. 359-362, 2003.

[22] L. Williams and R. L. Upchurch, "In support of student pair-programming," in Proceedings of the $32^{\text {nd }}$ SIGCSE Technical Symposium on Computer Science Education, vol. 33, no. 1, pp. 327-331, 2001.

[23] D. R. Compeau and C. A. Higgins, "Computer self-efficacy: Development of a measure and initial test," MIS Q., vol. 19, no. 2, pp. 189-211, 1995.

[24] T. Hill, N. D. Smith, and M. F. Mann, "Role of efficacy expectations in predicting the decision to use advanced technologies: The case of computers.," Journal of Applied Psychology, vol. 72, no. 2, p. 307-313, 1987.

[25] M. E. Gist, C. Schwoerer, and B. Rosen, "Effects of alternative training methods on self-efficacy and performance in computer software training.," J. Appl. Psychol., vol. 74, no.6, 1989.

[26] J. Webster and J. J. Martocchio, "Microcomputer playfulness: Development of a measure with workplace implications," MIS Q., vol. 16, no. 2, pp. 201-226, 1992.

[27] A. H. Maslow, "Dominance-feeling, behavior, and status.," Psychol. Rev., vol. 44, pp. no. 5,pp. 404-429, 1937.

[28] K. Young, J. Dollard, N. E. Miller, L. W. Doob, and H. A. Murray, "Frustration and aggression.," Am. Sociol. Rev., vol. 4, no. 4, p. 576, 1939.

[29] A. H. Maslow, Toward a Psychology of Being, 2nd Ed. Insight, 1968.

[30] M. G. Moore, "In Theory of transactional distance," Theor. Princ. Distance Educ., D. Keegan Ed., pp. 22-38, Routledge, 1997.

[31] M. Prince, "Does active learning work? A review of the research," J. Eng. Educ. vol. 
93, pp. 223-232, 2004.

[32] G. S. Stump, J. C. Hilpert, J. Husman, W.-T. Chung, and W. Kim, "Collaborative learning in engineering students: Gender and achievement," J. Eng. Educ., vol. 100, no. 3, pp. 475-497, 2011.

[33] L. Mason, "Sharing cognition to construct scientific knowledge in school context: The role of oral and written discourse," Instructional Science, vol. 26, no. 5. pp. 359$389,1998$.

[34] C. R. Greenwood, J. J. Carta, and R.V. Hall, "The use of peer tutoring strategies in classroom management and educational instruction.," School Psychology Review.vol.17, no.2, pp.258-275, 1988.

[35] B. Rogoff, Apprenticeship in Thinking: Cognitive Development in Social Context, Oxford University Press, 1991.

[36] H. J. Hartman, "Factors affecting the tutoring process," J. Dev. Educ., vol. 14, no.2, pp.2-4,1990.

[37] P. A. Cohen, J. A. Kulik, C. C. Kulik, "Educational outcomes of tutoring: A meta-analysis of findings," Am. Educ. Res. J., vol. 19, no. 2, pp. 237-248, 1982.

[38] C. A. Rohrbeck, M. D. Ginsburg-Block, J. W. Fantuzzo, and T. R. Miller, "Peer-assisted learning interventions with elementary school students: A meta-analytic review," J. Educ. Psychol., vol. 95, no. 2, pp. 240-257, 2003.

[39] S. Bandini, S. Manzoni, and G. Vizzari, "Agent based modeling and simulation: An informatics perspective,” J. Artif. Soc. Soc. Simul., vol. 12, no. 4, p. 4, 2009.

[40] D. Laurillard, "Rethinking University Teaching: A Framework for the Effective Use of Educational Technology." Routledge, 1993.

[41] C. Mimura and P. Griffiths, "A Japanese version of the Rosenberg Self-Esteem Scale: Translation and equivalence assessment," J. Psychosom. Res., vol. 62, no. 5, pp. 589594, 2007.

[42] A. Bandura, Social Foundations of Thought and Action: A Social Cognitive Theory. Prentice Hall, 1985.

[43] S. L. Britner and F. Pajares, "Self-efficacy beliefs, motivation, race, and gender in middle school science," J. Women Minor. Sci. Eng., vol. 7, no.4, pp. 269-283, 2001.

[44] E. Rienovita, M. Taniguchi, M. Kawahara, Y. Hayashi, and Y. Takeuchi, "Effect of human agent interaction improves self-esteem and students' motivation," in IIAI International Congress on Advanced Applied Informatics 2017, pp. 672-679. 